\title{
Practice of surgical treatment of breast cancer in china during the novel coronavirus COVID-19 outbreak
}

\author{
Hongjin Liu, Ling Xu, Yinhua Liu, Jingming Ye \\ Breast Disease Center, Peking University First Hospital, Beijing, China \\ Contributions: (I) Conception and design: None; (II) Administrative support: None; (III) Provision of study materials or patients: None; (IV) \\ Collection and assembly of data: None; (V) Data analysis and interpretation: None; (VI) Manuscript writing: All authors; (VII) Final approval of \\ manuscript: All authors. \\ Correspondence to: Yinhua Liu. Breast Disease Center, Peking University First Hospital, No.8 of XiShiKu Street, Beijing 100034, China. \\ Email: liuyinhua7520@163.com; Jingming Ye. Breast Disease Center, Peking University First Hospital, No.8 of XiShiKu Street, Beijing 100034,
}

China. Email: md_ye@sina.com.

\begin{abstract}
The corona virus disease 2019 (COVID-19) outbreak poses unprecedented challenges for patients, clinicians and healthcare systems. As hospital resources and staff become more limited during the COVID-19 outbreak, clinicians are facing many problems in managing breast cancer (BC) patients, such as how to define which patients require more urgent care and which patients can wait for treatment, how to manage the wards, operating rooms and staff, how to perform the postoperative management and follow-up of postoperative patients, etc. This article summarizes the experiences of surgical treatment of BC in China during the COVID-19 outbreak. Meanwhile, we hope that this article can provide clinicians in other affected areas valuable information so they don't have to enter the battlefield alone.
\end{abstract}

Keywords: Breast cancer; surgical treatment; corona virus disease 2019 (COVID-19); novel coronavirus

Received: 10 May 2020; Accepted: 11 June 2020; Published: 30 July 2020.

doi: $10.21037 /$ tbcr-20-18

View this article at: http://dx.doi.org/10.21037/tbcr-20-18

The corona virus disease 2019 (COVID-19) has shown a global outbreak trend. Even infected asymptomatic person can be infectious to normal people beside COVID-19 patients (1). Due to the characteristics of COVID-19 (such as the general susceptibility of population, the mode of transmission, and rapid progress of disease even faced with life-threatening in some patients), governments around the world are responding to the outbreak by using extreme medical power and taking various forms of isolation measures. As hospital resources become more limited during the COVID-19 outbreak, the treatment of patients with cancer or other diseases will definitely be affected. Breast cancer $(\mathrm{BC})$ is the malignant tumor with the highest incidence among all female malignant tumors. Surgery, an important part of cancer treatment, must be influenced by factors such as the adjustment of medical policies and the redistribution of medical resources. This article discusses the challenges and experiences of $\mathrm{BC}$ surgical treatment practices in China during the COVID-19 outbreak.

\section{Analysis of the impact of the COVID-19 outbreak on Chinese BC patients}

China is a densely populated country. After the COVID-19 outbreak was confirmed, the government quickly adopted regional isolation and concentrated national medical resources to support key epidemic areas. In other regions, the medical policies and the operation management of medical institutions also made with the corresponding adjustment. The advantage is to quickly and effectively minimize the COVID-19 outbreak, but it also causes difficulties in the diagnosis and treatment of $\mathrm{BC}$ patients with different extent.

BC patients especially those are undergoing chemotherapy 
are more susceptible to the COVID-19 because their immune systems are suppressed. At the same time, the normal diagnosis and treatment process of $\mathrm{BC}$ patients will definitely be affected by traffic restrictions, hospital visit restrictions and other factors. Patients may be delayed in diagnosis due to the suspension of imaging examinations and pathological biopsies in hospital. Newly diagnosed patients may not be hospitalized in time due to medical resources being preserved for virus-infected patients. Patients who are undergoing neoadjuvant chemotherapy (NAC) or adjuvant chemotherapy may not receive scheduled chemotherapy on time. Patients who plan to operate may not be completed on time. Patients who lived in remote area may not be able to finish the treatment at the hospital where they were initially treated due to regional traffic restrictions. Patients may not be able to conduct regular postoperative review on time due to outpatient visit restrictions. For these impacts, the government departments have made some adjustments. For example, for BC patients with endocrine therapy, the dosage limitation in the outpatient department has been adjusted from 1 to 3 months, so as to reduce the number of patients returning to the hospital and minimize exposure risk.

Surgery is an important part of the comprehensive treatment of BC patients. Patients eligible for breast conservation could reduce surgical trauma and preserve the appearance of breast beauty under the premise of radical tumor resection. For patient's ineligible for breast conservation, mastectomy is also a conventional method of $\mathrm{BC}$ surgery, which is safe and reliable and with low rates of local recurrence. For patients requiring mastectomy, immediate reconstruction with implant or tissue expanders can be performed to retain the appearance of breast. However, the routine diagnosis and treatment process during the COVID-19 outbreak cannot be completed as planned, and the surgery will also be delayed. For example, hospital requires that the hospitalized patient must be isolated in separated single room, thereby reducing the number of available beds, so the patient cannot be admitted to the hospital on time. Meanwhile, because most operation rooms in general hospitals cannot meet the requirements for the protection of respiratory tract infectious diseases, the number of operating rooms is reduced, which leads to the prolonged operation schedule. Some hospitals in key epidemic areas even suspended routine operations, and patients cannot receive surgical treatment.

Therefore, the impact of the COVID-19 outbreak on the $\mathrm{BC}$ treatment in China is comprehensive. Across every facet of treatment, clinicians should adapt the treatment strategy to the condition of patients.

\section{Analysis of the classification of BC surgical treatment during the COVID-19 outbreak}

In view of the impact and limitation of the routine surgical treatment during the COVID-19 outbreak, it is necessary to classify patients according to their conditions and formulate corresponding treatment strategies for patients with different grades to appropriately adjust the timing and method of surgery. For patients eligible for preoperative treatment (such as early BC patients with clinical stage T1-2N0, HR+, HER2-), neoadjuvant endocrine therapy can be considered, and surgical treatment should be considered after 3 to 6 months (2). For triple-negative BC (TNBC) and HER2 + BC above T2, neoadjuvant therapy can be performed before surgery.

Based on a series of studies (3-9), Liu et al. (10) showed that for patients with early breast cancer who are suitable for surgical treatment, appropriately delaying surgery after diagnosis would not significantly affect patient survival, so 12 weeks might be taken as a reasonable cut-off point for patients to postpone surgery during the COVID-19 outbreak. Meanwhile, for patients who have clinical completed remission after neoadjuvant chemotherapy, the principle of early surgery should still be followed, and postponing surgery to within 6 weeks after neoadjuvant chemotherapy is considered an acceptable cut-off point.

In the adjustment of surgical methods, breast conservation should be more recommended for patients who meet the indications, because it can significantly shorten the time of hospital stay. All types of immediate reconstruction have a higher incidence of postoperative complications and a prolonged duration time of operation and hospital stay. Therefore, immediate reconstruction especially autologous reconstruction should be deferred during the COVID-19 outbreak (11). The categories, patient description, treatment and adjustment recommendations during the COVID-19 outbreak are summarized in Table 1.

\section{Admission procedure and preoperative examination during the COVID-19 outbreak}

For BC patients who plan to undergo surgical treatment during the COVID-19 outbreak, each medical institution has formulated the admission procedure based on the comprehensive situation in different regions, including the 
Table 1 Categories for surgical treatment during the corona virus disease 2019 (COVID-19) outbreak

\begin{tabular}{|c|c|c|}
\hline Categories & Patient description & Treatment and adjustment recommendations \\
\hline $\begin{array}{l}\text { Grade A: } \\
\text { surgery in time }\end{array}$ & Neoadjuvant TNBC patients finishing treatment & $\begin{array}{l}\text { Operate as soon as possible unless the surgical resources } \\
\text { unavailable. If the delay exceeds } 4 \text { weeks, Patients can take } \\
\text { capecitabine first until operation }\end{array}$ \\
\hline \multirow{3}{*}{$\begin{array}{l}\text { Grade B: delay } \\
\text { surgery }\end{array}$} & Patients with $\mathrm{HR}+\mathrm{BC}$ & Neoadjuvant endocrine therapy \\
\hline & Patients with $\mathrm{HR}-/ \mathrm{HER} 2+\mathrm{BC}$ & Neoadjuvant chemotherapy or HER2 targeted therapy \\
\hline & Patients who can receive neoadjuvant therapy & $\begin{array}{l}\text { Initiate neoadjuvant therapy (may change systemic therapy to } \\
\text { ensure the safety) to defer surgery }\end{array}$ \\
\hline \multirow{3}{*}{$\begin{array}{l}\text { Grade C: } \\
\text { surgery is not } \\
\text { recommended }\end{array}$} & Patients who cannot tolerate surgery & $\begin{array}{l}\text { Include patients with a history of contact with suspected/ } \\
\text { confirmed COVID-19 cases }\end{array}$ \\
\hline & $\begin{array}{l}\text { Patients with local advanced } \mathrm{BC} \text { who are unable to } \\
\text { obtain R0 resection through routine surgery }\end{array}$ & $\begin{array}{l}\text { Consider systemic treatment and strive to convert into resectable } \\
\text { patients }\end{array}$ \\
\hline & $\begin{array}{l}\text { Patients with } \mathrm{mBC} \text { who require surgery of local } \\
\text { lesions }\end{array}$ & $\begin{array}{l}\text { Surgery should not be performed unless excisional biopsy is } \\
\text { performed to obtain pathological information }\end{array}$ \\
\hline
\end{tabular}

following contents.

\section{Epidemiological investigation before admission}

Include:

(I) Whether there is a travel or residence history of Hubei and surrounding areas;

(II) Whether there is a travel or residence history of the high-risk countries such as Italy, Iran, South Korea, Japan, the United States, Spain, etc.;

(III) Whether there is a travel or residence history of the community with documented COVID-19 positive cases;

(IV) Whether there is a history of contact with COVID19-infected persons (positive for nucleic acid detection);

(V) Does the patient have a fever or other upper respiratory tract infection symptoms;

(VI) Whether the patient is involved with COVID-19 disease clustering (2 or more cases with fever and/ or respiratory symptoms occur at such places as homes, offices, school classrooms, etc. within 2 weeks).
And fill in the "Notice of Investigation of the COVID-19 in Patients and Their Families".

\section{COVID-19 screening before admission}

(I) Chest CT examination was completed within 1 week before admission;

(II) The COVID-19-specific antibodies or nuclear acid were tested within 1 week before admission, and only negative patient can be hospitalized.

\section{Preoperative examination before admission}

In principle, as far as possible, preoperative examinations that require appointments should be completed before admission, including breast ultrasound, mammography, and dynamic contrast-enhanced magnetic resonance imaging (DCE-MRI) and necessary whole-body imaging evaluations, so as to shorten the time of hospital stay. Some blood test such as blood coagulation screening and infection screening can be completed after admission.

The doctor must reconfirm the patient's epidemiological investigation and other information at the time of 
admission, and inform the relevant regulations of the ward during this period (no leave, no visit, etc.).

\section{Requirements for ward and operation room during the COVID-19 outbreak}

As a place for residence and treatment, the ward and operating room must have higher requirements for sensory control management measures to ensure the safety of patients and staff.

\section{Quarantine strategy for surgical ward and staff}

(I) Zone arrangement and layout. If possible, the space of surgical ward unit should be rezoning follow the principle of "three zones and two passages": a contaminated zone, a potentially contaminated zone and a clean zone provided and clearly demarcated. In view of the fact that most of the surgical wards in general hospital does not have the conditions for ward transformation to a standard infectious ward unit, it shall set up an exclusive one-way passage at the entrance of the ward with a visible sign to restrict the direction and area of personnel flow, so as to achieve the effect of space division. All patients shall be isolated in separated single room and the patient's activity should be confined to the isolation ward to avoid cross infection.

(II) Staff management. All staff must receive strict training on how to deal with COVID-19 disease. Temperature needs to be measured before entering the ward. After entering the ward, all staff at the healthcare facilities must wear work uniform, cap and disposable surgical mask. Meanwhile, the management of hand hygiene must be strengthened (before aseptic operation, before contact with patient, after contact with patient, after contact with patient's blood or body fluids, and after contact with patient's surroundings or objects). Staff must wear disposable latex gloves, goggles and/ or protective face screen during invasive operation.

\section{Requirements for operation room and staff}

(I) Operation room arrangement. Depending on the hospital conditions, operation should be arranged in a negative pressure operating room (with an independent laminar flow unit if possible). During the operation, the buffer room and the operating room shall be tightly closed, and the operation must be carried out only if the operation room is under negative pressure.

(II) Staff management. All surgical personnel should put on disposable surgical mask and cap, latex gloves, etc. The surgeons and the hand-washing nurses should complete presurgical hand washing and wear disposable sterile operating clothes and sterile gloves as usual. Operation shall use disposable surgical items if possible. Irrelevant personnel shall be excluded from entering the operating room.

\section{Postoperative management during the COVID-19 outbreak}

Postoperative patients need to be closely observed and managed after returning to the ward. Postoperative fever is a common complication after operation, especially for BC patients who received NAC, because they are more likely than other patients to develop wound infections. During the COVID-19 outbreak, once the patient has fever, healthcare workers shall screen fever patients in accordance with the screening criteria. Staff must wear personal protective equipment to manage suspected/confirmed COVID-19 patients. No new patients should be hospitalized until the COVID-19 is excluded.

\section{Visit management}

Family visits and nursing shall be declined. Patients should be allowed to have their electronic communication devices to facilitate interactions with loved ones.

\section{Postoperative management}

(I) Change the wound dressing in time after the operation;

(II) Keep the drainage tube unblocked;

(III) Avoid the corresponding complications;

(IV) Arrange discharge as soon as possible depending on the patient's situation.

As of the writing of this article, the incidence of the COVID-19 in China has been effectively controlled and medical institutions at all levels are gradually returning to normal. The practice of BC patients' diagnosis and treatment strategies in special period is effective or not requires further observation. It is hoped that the experience in China can help surgeons in the world where the COVID-19 is still endemic. Facing unpredictable disease 
epidemic trends, medical institutions should formulate effective plans according to their own conditions and previous experience, so as to institutionalize and standardize the measures of infection control. Only in this way can we ensure that patients with cancer can also get safe, timely and effective treatment in special period.

\section{Acknowledgments}

Funding: This work was funded by The Beijing Medical Award Foundation (Grant number YXJL-2016-0040-0065).

\section{Footnote}

Conflicts of Interest: All authors have completed the ICMJE uniform disclosure form. (available at http://dx.doi. org/10.21037/tbcr-20-18). HL reports grants from The Beijing Medical Award Foundation, during the conduct of the study. YL serves as an unpaid editorial board member of Translational Breast Cancer Research from Mar 2020 to Feb 2022. JY reports grants from The Beijing Medical Award Foundation (Grant number YXJL-2016-0040-0065), during the conduct of the study. The other author has no conflicts of interest to declare.

Ethical Statement: The authors are accountable for all aspects of the work in ensuring that questions related to the accuracy or integrity of any part of the work are appropriately investigated and resolved.

Open Access Statement: This is an Open Access article distributed in accordance with the Creative Commons Attribution-NonCommercial-NoDerivs 4.0 International License (CC BY-NC-ND 4.0), which permits the noncommercial replication and distribution of the article with the strict proviso that no changes or edits are made and the original work is properly cited (including links to both the formal publication through the relevant DOI and the license). See: https://creativecommons.org/licenses/by-nc-nd/4.0/.

\section{References}

1. Wölfel R, Corman VM, Guggemos W, et al. Virological assessment of hospitalized patients with COVID-2019. Nature 2020;581:465-9.

2. Jiang Z, Li J. Ten hot issues on diagnosis and treatment of breast cancer under the outbreak of novel coronavirus pneumonia. Chinese Medical Journals Network 2020;100:721-3.

3. Yoo TK, Han W, Moon HG, et al. Delay of treatment initiation Does Not adversely affect survival outcome in breast cancer. Cancer Res Treat 2016;48:962-9.

4. Brazda A, Estroff J, Euhus D, et al. Delays in time to treatment and survival impact in breast cancer. Ann Surg Oncol 2010;17:291-6.

5. Polverini AC, Nelson RA, Marcinkowski E, et al. Time to treatment: measuring quality breast cancer care. Ann Surg Oncol 2016;23:3392-402.

6. Arciero C, Buhariwalla K, Liu Y, et al. Time from completion of Neo-adjuvant chemotherapy to surgery: effects on outcomes in breast cancer patients. Breast $\mathbf{J}$ 2020;26:155-61.

7. Sanford RA, Lei X, Barcenas CH, et al. Impact of time from completion of neoadjuvant chemotherapy to surgery on survival outcomes in breast cancer patients. Ann Surg Oncol 2016;23:1515-21.

8. Ladd S, Turner J. Neoadjuvant chemotherapy in breast cancer: does delayed surgery result in tumour progression? Clin Oncol 2017;29:e100.

9. Bleicher RJ, Ruth K, Sigurdson ER, et al. Time to Surgery and Breast Cancer Survival in the United States. JAMA Oncol 2016;2:330-9.

10. Liu Z, Jin Y, Fan Z. Timing and delays in early-stage breast cancer treatment during outbreaks of Corona Virus Disease 2019. Chinese Journal of Practical Surgery 2020;40:250-4.

11. Dietz JR, Moran MS, Isakoff SJ, et al. Recommendations for prioritization, treatment, and triage of breast cancer patients during the COVID-19 pandemic. the COVID-19 pandemic breast cancer consortium. Breast Cancer Res Treat 2020;181:487-97.

doi: $10.21037 /$ tbcr-20-18

Cite this article as: Liu H, Xu L, Liu Y, Ye J. Practice of surgical treatment of breast cancer in china during the novel coronavirus COVID-19 outbreak. Transl Breast Cancer Res 2020;1:18. 